\title{
Instrument inferences and verb schemata
}

\author{
BARBARA ANNE DOSHER \\ Columbia University, New York, New York 10027 \\ and

\begin{abstract}
ALBERT T. CORBETT
University of South Carolina, Columbia, South Carolina 29208
\end{abstract}

\begin{abstract}
Five studies employed a Stroop paradigm to examine the activation of instruments in sentence comprehension. Two types of instruments were studied, tools (e.g., spoon, hammer) and body parts (e.g., hand, wing). For example, is the concept "broom" activated by the sentence "The man swept the floor," or is the concept "wing" activated by the sentence "The duck flew over the pond"? Earlier studies have suggested that implicit instruments are not encoded in the underlying representation of a sentence during comprehension. The first four studies in the present paper reveal no evidence that abstract knowledge of the instruments is even activated. In the fifth study, the Stroop task reveals an effect if subjects are instructed to generate implicit instruments, although a facilitatory (rather than an inhibitory) effect is obtained.
\end{abstract}

Text comprehension is a highly inferential process. In comprehending "George ordered mussels in white wine," the reader will almost certainly infer that the activity is taking place in a restaurant, although this concept is not explicitly named. Moreover, having induced this inference, the writer will rely on the reader's knowledge of restaurants in subsequent descriptions of events (Bobrow \& Norman, 1975; Norman \& Bobrow, 1979). For instance, in reading "George left ten dollars on the table and went to pay the bill," the reader can infer that the $\$ 10$ is a tip and that George is generous rather than forgetful. Such knowledge of typical activities in a restaurant is a well known example of a schema (Bartlett, 1932; Bobrow \& Norman, 1975; Rumelhart, 1975) or script (Schank \& Abelson, 1977). A schema is a memory structure that represents abstract knowledge of an activity or situation, components of the activity, and the relations between the components (a script represents a situation with a fairly rigid sequence of component activities). A schema contains knowledge about necessary and likely activities (e.g., the customer must order and is likely to eat the food at the restaurant) and unlikely activities (the customer is unlikely to yell at his companions). A schema also contains information on necessary or likely actors (customers, waiter) and objects (food, utensils). This information includes both necessary constraints (e.g., the customer must be animate) and typical examples (e.g., George is more likely to use a fork than chopsticks to eat his mussels).

This research was supported by grants from the National Institutes of Education (NIE-G-77-0008 NIE-G-80-0175), the Spencer Foundation, and the Columbia University Council for the Social Sciences.
Recent research has examined the influence of schemata in recall of sentences and text (Anderson \& Pichert, 1978; Bower, Black, \& Turner, 1979; Bransford \& McCarrell, 1974; Graesser, Gordon, \& Sawyer, 1979; Hasher \& Griffin, 1978; Reder \& Anderson, 1980; Smith, Adams, \& Schorr, 1979). In the present paper, alternatively, we attempt to examine principles of schema function during comprehension with a more on-line measure of activation.

Specifically, we investigate whether highly typical schema components are necessarily activated when a schema is accessed. The focus is on the activation of implicit instruments (objects, either tools or body parts, employed to accomplish an action). For example, the schema for stirring coffee includes the information that a tool is used, that it must be rigid and fit in the container, that the agent is probably holding the instrument in his or her hand, and that the instrument is typically a spoon. We investigate whether, in reading "Mary stirred her coffee," the highly typical implicit instrument "spoon" is activated. These kind of verb-related schemata are simpler than the restaurant schema described earlier, but examination of this simpler case may demonstrate the same principles of access (Schank, 1975).

\section{Activation vs. Instantiation}

In reading, activation of an abstract schema component can be logically distinguished from instantiation, that is, encoding an inference on the basis of the abstract information. In reading "Mary stirred her coffee," activation of the abstract concept "spoon" can be distinguished from the encoding of a specific example of the concept "spoon" as part of the representation of the sentence in memory. Prior research has examined whether or not highly likely instrument inferences are 
routinely drawn during sentence comprehension. Evidence consistent with both alternatives has been obtained (Corbett \& Dosher, 1978; Johnson, Bransford, \& Solomon, 1973; Paris \& Lindauer, 1976; Singer, 1976, 1979, 1980). Paris and Lindauer (1976) presented perhaps the strongest evidence that such inferences are routinely drawn. They demonstrated that a typical implicit instrument is as good a cue in sentence recall as a typical instrument explicitly referenced in learning. That is, "shovel" is about as good a recall cue for "The lawyer dug a hole" as for "The lawyer dug a hole with a shovel." However, Corbett and Dosher (1978) presented evidence that recall cue effectiveness may be mediated by schematic knowledge at retrieval and need not reflect encoding of an implicit instrument in learning. In this study, typical instruments were still as effective as sentence recall cues when an alternative, less likely instrument was present in learning (e.g., "The lawyer dug a hole with a pitchfork"). Moreover, Corbett and Dosher (1978) argued that implicit instruments are not automatically encoded in reading, since subjects were highly accurate at discriminating explicit and implicit instruments in recall.

Singer $(1979,1980)$ has also argued that implicit instruments are not automatically inferred when a schema is activated in reading, based on reaction time results. In several of these studies, subjects read a short description of an activity that involves a likely instrument and then were asked a true-false question about the likely instrument. Subjects were faster at verifying the likely instrument and faster at rejecting an impossible instrument when the likely instrument had been explicitly referenced in the text. In a second study, subjects read a sentence describing an activity that either explicitly or implicitly referenced a likely instrument. Reading time for a subsequent reference to the likely instrument was slower if the original sentence had not explicitly mentioned the instrument. (Based on a control condition, Singer argues that this effect is based on the underlying representation of sentence meaning and not just repetition of the instrument word in the surface structure.)

The question remains, however, whether schema access results in a top-down activation of highly typical schema components in reading. Such activation need not be sufficient for instantiation or encoding an inference, so a conclusion that implicit instruments are not encoded does not preclude activation of those schema constituents. A variety of studies have demonstrated that concept access may result in a spread of activation to related concepts in memory (Collins \& Loftus, 1975; Fischler, 1977a, 1977b; Loftus, 1973; McKoon \& Ratcliff, 1979, 1980a, 1980b; Meyer \& Schvaneveldt, 1971; Neely, 1977; Ratcliff \& McKoon, 1978, 1981; Schvaneveldt \& Meyer, 1973). Some indicate that this spread is, in part, an automatic process (Fischler, 1977a; Neely, 1977; Ratcliff \& McKoon, 1981). The present paper, therefore, examines whether schema access may result in activation of typical implicit instruments: Activation is examined for two classes of instrument, tools (broadly defined as any inanimate object used to accomplish some action; e.g., "broom" for "sweeping the floor") and body parts (e.g., "fingers" for "typing") across five experiments.

\section{Paradigm}

This paper employs the Stroop paradigm to assess on-line instrument activation in reading. In a Stroop task, a string of characters is presented in colored ink and the subject names the ink color. Response time is lengthened if the characters form a word (particularly a color name other than the ink color) relative to a neutral character string (e.g., asterisks). This Stroop interference has been attributed primarily to competition between a reading and a color naming response (Keele, 1972; Klein, 1964; Stroop, 1935). Stroop interference for a word increases further if that word is preceded by a semantically related stimulus (Conrad, 1974; Warren, 1972). Thus, activation of a target word (or corresponding concept) typically increases response time in a Stroop task relative to an out-of-context control. In the present investigation, subjects are presented a sentence prime followed by an instrument name in colored ink. If an instrument is activated by a prime sentence that references its activity schema, then response time to name the ink color should be slowed relative to an out-of-context control (in which the instrument follows an unrelated sentence). Conrad (1974) and Tanenhaus, Flanigan, and Seidenberg (1980) employed a similar design in studying activation of mutliple mean. ings in comprehension of ambiguous words, and the paradigm has in general been used as an index of automatic activation of tested concepts.

\section{EXPERIMENT 1}

This experiment examines whether tool instruments are activated when a reader comprehends a sentence. For example, does reading the sentence "The architect stabbed the man" result in the activation of the most likely instrument, "knife"? Second, it examines whether activation of instruments is restricted to the single most likely instrument (e.g., knife) or whether it extends to the second most likely instrument (e.g., ice pick).

\section{Method}

Subjects. Eight undergraduates volunteered to participate in this experiment for course credit. They served in two separate 45-min sessions on 2 different days.

Stimuli and Design. Sixty predicate frameworks were selected from instrument completion norms (Corbett \& Dosher, Note 1). In those norms, 100 subjects were presented sentences like "He tightened the bolt with a(n)__ " and asked to generate two possible instruments. Note that the instruments in this study are not uniquely determined by the sentence (e.g., one might 
tighten a bolt with a wrench or with pliers). Instrument completion norms provide a measure of how probable a particular instrument is. Along with each of the 60 predicates, the highest frequency instrument and second highest frequency instrument (ignoring order of response) were selected to serve as Stroop stimuli in this experiment. The average production frequency of these responses was 80.2 for highest associates and 41.0 for the second highest. The predicates and two instruments are listed in Appendix A, along with completion frequencies.

A single sentence served as the priming stimulus on each trial and was followed by a Stroop stimulus that was an instrument. Each of the 120 instruments appeared twice across the experiment, once in context and once out of context. Thus there were a total of 240 trials, and each predicate appeared four times. The list order was randomized with the constraints that each predicate appear once in each quarter of the trials and one of the two instruments for a given predicate appear once in each quarter. The order of trials was also checked for unintended cross-trial priming. Out-of-context pairings were generated by randomly repairing each Stroop word with a new predicate.

Apparatus and Procedure. The Stroop words were centered on white index cards and printed with a Gothic .5-in. stencil in red, yellow, green, or blue ink. The Stroop words appeared in the same color both in and out of context. Priming sentences were centered on white index cards and typed in a large IBM 6-pitch font.

The stimulus cards were displayed using a Scientific Prototype three-channel tachistoscope. A field with centered fixation dot was shown during all intertrial intervals. After saying "ready," the experimenter initiated each trial sequence. The sentence prime stimulus then appeared immediately, centered above the location of the fixation dot. Subjects were instructed to read the sentences silently. After $2.5 \mathrm{sec}$, the sentence was removed and the Stroop word appeared, centered below the sentence. The Stroop word remained illuminated until either the subject responded or $3 \mathrm{sec}$ elapsed. The next trial was initiated as soon as the next display was set up. Vocal Stroop responses were monitored by a Scientific Prototype voice relay, and the timing was performed by a Hunter millisecond timer and Hunter digital display. The experimenter ordered the stimulus cards, monitored the responses, and recorded the data.

\section{Results and Discussion}

Concept priming results in slower reaction times in a Stroop task (Warren, 1972). The primed word apparently interferes with generating the ink-color name more than an unprimed word. If sentence comprehension results in instrument activation, response times should be slower for instrument Stroop stimuli in context than out of context.

Fifty-four of 1,920 trials (about 2.8\%) were lost over the course of the experiment, almost entirely due to mechanical difficulties with the voice key related to uncontrollable background noise. Almost no data were lost due to subject response error. Lost trials were approximately evenly distributed across conditions. The missing trials were replaced with the reaction time from the paired context condition (Winer, 1971). The results do not provide any evidence for tool instrument priming. Mean response times for the highest frequency instruments in and out of context were 872 and $875 \mathrm{msec}$ $[t-1(7)=-.24$, n.s.; $t-2(59)=-.19$, n.s. $]$. (Note, $t-1$ is an analysis on subject means, and $t-2$ is an analysis on item means.) The corresponding values for the second highest frequency instruments were 859 and $840 \mathrm{msec}$ $[\mathrm{t}-1(7)=1.09$, n.s.; $\mathrm{t}-2(59)=1.51$, n.s. $]$. Thus, both Stroop effects were nonsignificant. An additional analysis was performed on only those instruments with completion frequencies of 95 or more, since it is possible that only extremely likely instruments are activated during sentence comprehension. There were 16 instruments in this range. Response times in and out of context were 874 and $871 \mathrm{msec}$, respectively $[\mathrm{t}-1(7)=.24$, n.s.] .

To insure that the repeated testing in this experiment did not obscure a real tendency toward instrument priming, a separate analysis was performed on only the first presentation of each predicate. Fifteen items appeared in each condition in this analysis (each predicate appeared in all four conditions across subjects). Response times were slower for these early tests, but again, no evidence of instrument priming was obtained. Mean response times for the highest frequency instruments in and out of context were 914 and $927 \mathrm{msec}$ $[\mathrm{t}-1(7)=-.32$, n.s. $]$. The corresponding values for the second highest frequency instruments were 903 and $899 \mathrm{msec}[\mathrm{t}-1(7)=.09$, n.s. $]$.

No evidence of instrument priming was obtained in this study. This was true despite quite substantial sample sizes. We found this result somewhat surprising and felt that it should be replicated.

\section{EXPERIMENT 2}

This experiment replicates Experiment 1 in all respects except for the inclusion of a sentence reading check. It was unlikely, but possible, that the subjects in Experiment 1 were simply not reading the prime sentences. As an assurance against this strategy, a few catch trials, or anomalous sentences, were included in the present study. Subjects were told that there would be a few sentence primes that did not make sense and were asked to report these sentences.

\section{Method}

Subjects. Seven undergraduates volunteered to participate for course credit. They served in two separate 45 -min sessions on different days. An eighth subject was dropped when we discovered that Spanish was his primary language.

Design, Stimuli, Apparatus, and Procedure. These were identical to Experiment 1 , except that 24 nonsense sentences were distributed randomly throughout the stimulus list as catch trials. Thus, there were a total of 264 trials in this experiment. Subjects were instructed to say "nonsense" after naming the ink color of the Stroop stimulus in those few instances in which the priming sentence was nonsensical. Performance on this task was virtually perfect.

\section{Results and Discussion}

Eighty-four of 1,848 trials were lost (about 4\%), almost entirely due to mechanical difficulties, and were replaced by the method described earlier. Again, no evidence of instrument priming was obtained (see 
Table 1

Mean Stroop Reaction Times for Experiments 1 and 2

\begin{tabular}{|c|c|c|c|c|c|c|}
\hline & \multicolumn{2}{|c|}{ Experiment 1} & \multicolumn{2}{|c|}{ Experiment 2} & \multicolumn{2}{|c|}{ Average } \\
\hline & I & 0 & I & 0 & $\mathrm{I}$ & 0 \\
\hline Highest Production Instruments* & 872 & 875 & 950 & 948 & 909 & 909 \\
\hline Second Highest Production Instruments** & 859 & 840 & 957 & 948 & 905 & 891 \\
\hline Instruments With Completion Frequencies $\geqslant 95$ & 874 & 871 & 947 & 960 & 911 & 915 \\
\hline
\end{tabular}

Note $-I=$ in context; $O=$ out of context. $\quad n_{n}=60$ trials $/$ subject $\times 8$ subjects $=480$ trials $/$ mean. $\quad * *_{n}=16$ trials $/$ subject $\times 8$ sub. jects $=128$ trials $/$ mean.

Table 1). Mean response times for the highest frequency instruments in and out of context were 950 and $948 \mathrm{msec}$ $[\mathrm{t}-1(6)=.36$, n.s.; $\mathrm{t}-2(59)=.19$, n.s. $]$. The values for the second highest frequency instruments were 957 and $948 \mathrm{msec}[\mathrm{t}-1(6)=.59$, n.s.; $\mathrm{t}-2(59)=.85$, n.s. $]$. Mean response times were also calculated for only the 16 instruments with completion frequencies greater or equal to 95 . Those times in and out of context were 947 and $960 \mathrm{msec}[\mathrm{t}-1(6)=-.74$, n.s.]. The analysis for the first tests only of each item also supported these conclusions. The mean response times in and out of context for the highest frequency instruments were 1,060 and $1,040 \mathrm{msec}[\mathrm{t}-1(6)=.61, \mathrm{n.s}$.$] ; for the$ second highest frequency instruments, they were 1,044 and $1,051 \mathrm{msec}[\mathrm{t}-1(6)=-.18, \mathrm{n} . \mathrm{s}$. $]$. These results confirm the conclusion of the prior experiment that tool instruments do not seem to be activated when a related sentence is processed.

The inclusion of a check for reading of the prime sentence did not alter the results, which indicate no spontaneous activation of tool instruments following the reading of an individual sentence. Notice that this conclusion still holds when the results of Experiments 1 and 2 are averaged (see Table 1), and each mean is based on as many as 900 trials (all ts nonsignificant).

\section{EXPERIMENT 3}

Experiment 3 further replicates the findings concerning activation of tool instruments like "He hit the ball (with a bat)" and looks for activation in a different set of instruments, body-part instruments like "He bit the apple (with teeth)." Although we failed to find evidence for activation of tool instruments in Experiments 1 and 2, body-part instruments might behave differently for a variety of reasons.

First, body-part instruments may be activated simply because they are associates of the verb alone in this study, whereas the tool instruments are typically associated with the verb-object pair. For example, "teeth" are associated with "biting," but "bats" are associated with "hitting a ball" rather than "hitting" alone. Second, the body-part instruments are, in general, determined by the schema and are obligatory components of the agent, but neither of these is generally true of the tool instruments. That is, to run or kick (in the animate sense), the agent must have legs as an intrinsic component; hitting a ball does not require a bat, and "having a bat" is not an intrinisic property of the agent (even if a bat is being used). For these reasons, body-part instruments might be activated as part of the normal constraint-checking process in sentence comprehension (which allows us to reject a literal interpretation of "The fish kicked the stone"). It should be noted, however, that constraints on the verbs in this study may be stated in terms of category membership (e.g., birds, land mammals, and arthropods are acceptable agents of kick, but fish are not). So, constraint checking logically need not involve body-part activation.

\section{Method}

Subjects. Twenty-four undergraduates volunteered to participate in the experiment for course credit. The experiment took about $30 \mathrm{~min}$.

Stimuli and Design. We selected a list of 12 body-part instruments and their respective verbs. This was as many instruments as we could generate that were distinct from each other and subject to the restriction that none be a high associate to its verb in pretesting norms. A set of 12 tool instruments was then selected from among those with highest production frequency. (Stimuli are listed in Appendix B.)

These 24 instruments appeared both in related and unrelated sentence contexts over the course of the experiment. There were 24 additional noninstrument stimuli included at the beginning of the list and as fillers. Trials were randomized subject to the constraint that related and unrelated tests occur in different halves of the trials.

Apparatus and Procedure. The apparatus, procedure, and physical stimulus characteristics were the same as those of the previous experiments.

\section{Results and Discussion}

Thirty trials (of 1,296 ) were lost (about $2 \%$ ), almost exclusively due to mechanical error. The mean response times are listed in Table 2. The mean response times for tool instruments in and out of context, respectively, were 928 and $926 \mathrm{msec}[\mathrm{t}-1(26)=.10$, n.s.]. The values

Table 2

Mean Reaction Times for Experiments 3 and 4

\begin{tabular}{|c|c|c|c|c|c|c|}
\hline & \multicolumn{2}{|c|}{$\begin{array}{l}\text { Experi- } \\
\text { ment } 3^{*}\end{array}$} & \multicolumn{2}{|c|}{$\begin{array}{c}\text { Experi- } \\
\text { ment } 4 * *\end{array}$} & \multicolumn{2}{|c|}{ Average } \\
\hline & I & 0 & I & 0 & I & 0 \\
\hline $\begin{array}{l}\text { Tool Instruments } \\
\text { Body-Part Instruments }\end{array}$ & $\begin{array}{l}928 \\
904\end{array}$ & $\begin{array}{l}926 \\
886\end{array}$ & 892 & 914 & 898 & 899 \\
\hline
\end{tabular}

Note $-I=$ in context; $O=$ out of context. $\quad{ }_{n} n=12$ stimuli per cell per subject $\times 27$ subjects $=324$ trials $/$ mean. $\quad * n=12$ stimuli per cell per subject $\times 14$ subjects $=168$ trials $/$ mean. 
for the body-part instruments were 904 and $886 \mathrm{msec}$, respectively $[\mathrm{t}-1(26)=.83$, n.s. $]$. There was no evidence for activation or generation of either type of instrument while reading the sentence primes of this study.

\section{EXPERIMENT 4}

Experiment 4 replicated these findings for the bodypart instruments in an environment that contained no in-context tool instruments. While there was no evidence for the generation of tool instruments in the previous study, we wanted to test the body-part instruments without the distraction of other types of tested instruments. Since body-part instruments are the only ones to appear in context, this increases the chances that subjects would notice the prime-test relations and begin to actively generate body-part continuations. In this sense, it is more comparable to Experiments 1 and 2.

\section{Method}

Subjects. Fourteen undergraduate volunteers served as subjects for course credit. The experiment took about $30 \mathrm{~min}$.

Stimuli and Procedure. The experiment was identical to Experiment 3, except that the tool instrument Stroop stimuli were replaced with additional filler stimuli.

\section{Results and Discussion}

Only 1 of the 336 body-part trials was lost. The mean response times for the body-part instruments in and out of context were 892 and $914 \mathrm{msec}$, respectively $[t-1(13)=1.19, n . s$.$] . Thus there was no evidence that$ body-part instrument information was activated while reading the sentences of either of these studies. ${ }^{1}$

\section{EXPERIMENT 5}

Experiment 5 examined activation of instruments when subjects were explicitly instructed to generate them while reading each stimulus sentence. The claim of earlier investigators (Paris \& Lindauer, 1976) was that instruments were not only passively activated in reading simple sentences, but actually generated and encoded (although not necessarily "named" subvocally). This experiment should determine the measurable consequences in this paradigm of the (instructed) act of instrument generation.

\section{Method}

Subjects. Six undergraduates volunteered to participate in the experiment for course credit. The single session lasted about $30 \mathrm{~min}$.

Stimuli and Procedure. The stimuli and procedure were identical to that of Experiment 3, except that the body-part instruments and tool instruments were tested in separate blocks of trials and fillers were excluded. This was necessary for clear instructions on instrument generation. Prior to each block, the subjects were instructed to silently generate the most likely tool (or body-part) instrument. Several examples were discussed, but the subjects were not asked for their subjective responses during the test trials. Three of the subjects received the tool instruments first, and the remaining three received the stimuli in the other order.

\section{Results and Discussion}

There were 288 relevant trials, of which none were lost. Mean response times are shown in Table 3. For tool instruments in and out of context, mean response times were 960 and $1,116 \mathrm{msec}$, respectively. This is a difference of $156 \mathrm{msec}[\mathrm{t}-1(5)=4.27, \mathrm{p}<.05 ; \mathrm{t}-2(11)=2.38$, $p<.05]$. For body-part instruments in and out of context, mean response times were 1,072 and $1,148 \mathrm{msec}$, respectively. This is a difference of $76 \mathrm{msec}[\mathrm{t}-1(5)=$ $2.98, \mathrm{p}<.05 ; \mathrm{t}-2(11)=1.89, \mathrm{p}<.10]$.

Thus, when subjects are given explicit instructions to generate instruments, there is clear evidence of a context effect on the Stroop responses. This is true despite the small number of subjects used in this experiment. (Each mean was based on 72 trials, compared to $300+$ in earlier experiments.)

The nature of the Stroop effect is unusual and deserves some comment. The in-context conditions here, with instructions to generate, showed Stroop response times that were actually faster than those for the out-of-context responses. This is the opposite direction of the more typical Stroop interference effects. However, it is important to note that Stroop facilitation (other than simple congruency) has been reported in the literature. Neill $(1977,1978)$ reported Stroop facilitation under some conditions of priming. He found facilitation when the response from the preceding trial matched the distractor word on the current trial. That is, he found faster responses to the word "red" printed in green when preceded by "blue" printed in red relative to an unrelated control condition of "red" printed in green preceded by "blue" printed in yellow. His situation is analogous to the current manipulation that produced facilitaiton, in that the implicit response involved in instrument generation matches the Stroop word in the related context condition. A similar finding was reported by Dyer (1971), who found that a preview of the Stroop word reduced interference in a Stroop-like task. These effects are interesting, and there are a number of possible explanations. Dyer suggested that a preview facilitated encoding of the distractor word when it was again presented. An alternative possibility is that when the distractor word is consciously encoded or generated, it undergoes a short refractory period. Neill (1978) believes that the explanation lies not in a refractory period, but in the number of activated responses (for a discussion, see Hintzman, Carre, Eskridge, Owens, Sparks, \& Shaff, 1972; Neill, 1977, 1978).

Whatever the explanation, the important point here is that conscious generation of instruments leads to a

Table 3

Mean Stroop Reaction Times for Experiment 5 (Instructed Generation)

\begin{tabular}{lcc}
\hline & In Context & Out of Context \\
\hline Tool Instruments & 1072 & 1148 \\
Body-Part Instruments & 960 & 1116 \\
\hline
\end{tabular}

Note $-n=12$ stimuli per cell per subject $\times 6$ subjects $=72$ trials $/$ mean. 
recognizable pattern of context effects that are easily detectable, even with a very small number of subjects. Yet, with many more subjects and stimuli in the earlier experiments, there was no suggestion of either conscious instrument generation or the more typical Stroop inhibition that normally results from passive activation processes. $^{2}$

\section{GENERAL DISCUSSION}

These studies were designed to examine the activation of implicit world knowledge in sentence comprehension. In particular, they focus on the activation of one implicit component of certain simple activity schemata: the instrument. Although the Stroop paradigm revealed evidence of instrument activation when subjects were instructed to generate implicit instruments in Experiment 5, Experiments 1.4 revealed no evidence of instrument activation in the absence of such instructions. Thus, instrument activation does not appear to be a general or automatic component of sentence comprehension.

Corbett and Dosher (1978) and Singer (1979) have argued that general knowledge of probable instruments is not routinely employed to encode instrument inferences in reading single sentences (i.e., to incorporate an instance of the implicit instrument as part of the proposition being encoded). While such an inference would very likely be correct, it does not seem to be necessary or useful in sentence comprehension, since, by definition, the inference amounts to redundant encoding of the abstract information concerning instruments. The results of the present research reinforce this conclusion, since it appears that the abstract knowledge of implied instruments is not automatically activated in processing sentences.

While abstract knowledge of highly probable instruments may not be automatically activated in comprehension, there must certainly be circumstances in which one could find evidence of such activation. In fact, McKoon and Ratcliff (1981) have presented evidence of instrument activation under somewhat different circumstances. In their study, subjects read five-sentence paragraphs. In the critical trials, the last sentence described an activity that accepted a highly probable implicit instrument (e.g., "Bobby pounded the board together with nails") and the first sentence referenced either the highly probable instrument ("Bobby got a saw, hammer, screwdriver and square from his toolbox") or a less likely instrument (e.g., substituting "mallet" for "hammer"). McKoon and Ratcliff found evidence in a probeword recognition memory task that the highly likely instrument (but not the less likely instrument) was activated when subjects read the last sentence in the paragraph.

There are at least two important ways in which the McKoon and Ratcliff (1981) studies vary from the present studies (other than the dependent variable), and either (perhaps both) may well have contributed to the difference in results. First, subjects in the McKoon and Ratcliff study read paragraphs rather than single sentences. It may be that reading a preliminary set of related sentences leads to a different pattern of automatic activation of an activity schema. Alternatively, subjects may adopt a different strategy of component activation in reading full paragraphs.

The second, and perhaps more important, difference is that in the McKoon and Ratcliff (1981) studies, the instruments that were implicit in the final sentence of the paragraphs were explicitly referenced earlier in the paragraphs (as they must be, if a probe recognition paradigm is to be employed). In this situation, the activation of the implicit schema component and encoding of the instrument inference can serve a useful function, that of integrating the initial and final sentences of the paragraphs. Indeed, McKoon and Ratcliff provide evidence with a second type of probe recognition task that the highly probable instruments referenced in the first sentence are, in fact, encoded as the instrument in the underlying representation of the final sentence.

McKoon and Ratcliff (1981) also provide some boundary information on this integrative process. They found no evidence of activation or integration with the unlikely instruments (e.g., mallet). Also, they found that an earlier reference to a likely instrument was not sufficient to obtain integration if the reference itself precluded a meaningful integration. That is, no evidence of integration of the initial and final sentences in the text structure was found when the initial sentence read "Bobby opened his toolbox and pulled out a mallet, a hammer which had been broken earlier that week, and a screwdriver." (McKoon and Ratcliff did not examine whether there was any activation of the implicit instrument in reading the fifth sentence in this condition.)

While McKoon and Ratcliff (1981) demonstrate that implicit instruments may be activated and encoded in reading, the results of the present study (along with Corbett \& Dosher, 1978; Singer, 1979) indicate that these are not automatic processes. Instead, such highly probable inferences may be activated and encoded only when they serve a specific purpose in comprehension, for example, in integrating propositions in a paragraph.

\section{REFERENCE NOTE}

1. Corbett, A. T., \& Dosher, B. A. Instument completion norms of 67 sentences. Manuscript available from A. T. Corbett, Department of Psychology, University of South Carolina, Columbia, South Carolina 29208, and B. A. Dosher, Columbia University, New York, New York 10027.

\section{REFERTNCES}

Anderson, R. C., \& Pichert, J. W. Recall of previously unrecallable information following a shift in perspective. Journal of Verbal Learning and Verbal Behavior, 1978, 17, 1-12.

BARTLET, F. C. Remembering: A study in experimental and social psychology. New York: Macmillan, 1932.

Bosnow, D. G., \& Norman, D. A. Some principles of memory schemata. In D. G. Bobrow \& A. M. Collins (Eds.), Repre- 
sentation and understanding: Studies in cognitive science. New York: Academic Press, 1975.

Bower, G. H., Black, J. B., \& TuRner, T. J. Scripts in memory for text. Cognitive Psychology, 1979, 11, 177-220.

Bransford, J. D., \& McCarrell, N. A. A sketch of a cognitive approach to comprehension. In W. Weimer \& D. Palermo (Eds.), Cognition and the symbolic processes. Hillsdale, N.J: Erlbaum, 1974.

Collins, A. M., \& Lofrus, E. F. A spreading activation theory of semantic processing. Psychological Review, 1975, 82, 407428.

Conrad, C. Context effects in sentence comprehension: A study of the subjective lexicon. Memory \& Cognition, 1974, 2, 130-138.

Corbett, A. T., \& Dosher, B. A. Instrument inferences in sentence encoding. Journal of Verbal Learning and Verbal Behavior, 1978, 17, 479-491.

DYER, F. N. The duration of word meaning responses: Stroop interference for different preexposures of the word. Psychonomic Science, 1971, 25, 229-231.

Fischler, I. Associative facilitation without expectancy in a lexical decision task. Journal of Experimental Psychology: Human Perception and Performance, 1977, 3, 18-26. (a)

Fischler, I. Semantic facilitation without association in a lexical decision task. Memory \& Cognition, 1977, 5, 335-339. (b)

Graesser, A. C., Gordon, S. E., \& Sawyer, J. D. Recognition memory for typical and atypical actions in scripted activities: Tests of a script pointer plus tag hypothesis. Journal of Verbal Learning and Verbal Behavior, 1979, 18, 319-332.

Hashen, L., \& GRIfFin, M. Reconstructive and reproductive processes in memory. Journal of Experimental Psychology: Human Learning and Memory, 1978, 4, 318-330.

Hintzman, D. L., Carre, F. A., Eskridge, V. L., Owens, A. M., Sparks, M. E., \& Shaff, S. S. Stroop effect: Input or output phenomenon? Journal of Experimental Psychology, $1972,95,458-459$.

Johnson, M. K., Bransford, J. D., \& Solomon, S. K. Memory for tacit implications of sentences. Journal of Experimental Psychology, 1973, 98, 203-205.

KeELE, S. W. Attention demands of memory retrieval. Journal of Experimental Psychology, 1972, 93, 245-248.

KLEIN, G. S. Semantic power measured through the interference of words with color naming. American Journal of Psychology, $1964,72,576-588$.

LofTUs, E. F. Activation of semantic memory. American Journal of Psychology, 1973, 86, 331-337.

McKoon, G., \& Ratcliff, R. Priming in episodic and semantic memory. Journal of Verbal Learning and Verbal Behavior, $1979,18,463-480$.

McKoon, G., \& Ratcliff, R. The comprehension processes and memory structures involved in anaphoric reference. Journal of Verbal Learning and Verbal Behavior, 1980, 19, 668-682. (a)

McKoon, G., \& Ratcliff, R. Priming in item recognition: The organization of propositions in memory for text. Journal of Verbal Learning and Verbal Behavior, 1980, 19, 369-386. (b)

McKoon, G, \& Ratcliff, R. The comprehension processes and memory structures involved in instrumental reference. Journal of Verbal Learning and Verbal Behavior, 1981, 20, 671-682.

Meyer, D. E., \& Schvanefeldt, R. W. Facilitation in recognizing pairs of words: Evidence of a dependence between retrieval operations. Journal of Experimental Psychology, 1971, 90, 227-243.

NEELY, J. H. Semantic priming and retrieval from lexical memory: Roles of inhibitionless spreading activation and limited-capacity attention. Journal of Experimental Psychology: General, 1977, 106, 226-2S4.

NeILL, W. T. Inhibitory and facilitatory processes in selective attention. Journal of Experimental Psychology: Human Learning and Memory, 1977, 3, 444-450.
NeilL, W. T. Decision processes in selective attention: Response priming in the Stroop color-word task. Perception \& Psychophysics, 1978, 23, 80-84.

Norman, D. A., \& Boвrow, D. G. Descriptions: An immediate stage in memory retrieval. Cognitive Psychology, 1979, 11, 107-123.

Paris, S. C., \& Lindauer, B. K. The role of inference in children's comprehension and memory for sentences. Cognitive Psychology, 1976, 8, 217-227.

Ratcliff, R., \& McKoon, G. Priming in item recognition: Evidence for the propositional structure of sentences. Journal of Verbal Learning and Verbal Behavior, 1978, 17, 403-417.

RATClifF, R., \& McKoon, G. Automatic and strategic priming in recognition. Journal of Verbal Learning and Verbal Behavior, 1981, 20, 204-215.

REDer, L. M., \& ANDERson, J. R. A partial resolution of the paradox of interference: The role of integrating knowledge. Cognitive Psychology, 1980, 12, 447-472.

Rumelhakt, D. E. Notes on a schema for stories. In D. G. Bobrow \& A. M. Collins (Eds.), Representation and understanding. New York: Academic Press, 1975.

Schank, R. C. The structure of episodes in memory. In D. G. Bobrow \& A. M. Collins (Eds.), Representation and understanding. New York: Academic Press, 1975.

Schank, R. C., \& Abelson, R. P. Scripts, plans, goals and understanding. Hillsdale, N.J: Erlbaum, 1977.

Schvaneveldt, R. W., \& Meyea, D. E. Retrieval and comparison processes in semantic memory. In $S$. Kornblum (Ed.), Attention and performance IV. New York: Academic Press, 1973.

Singen, M. Context inferences in the comprehension of sentences. Canadian Journal of Psychology/Review of Canadian Psy. chology, 1976, 30, 39-46.

Singer, M. Processes of inference during sentence encoding. Memory \& Cognition, 1979, 7, 192-200.

Singer, M. The role of case-filling inferences in the coherence of brief passages. Discourse Processes, 1980, 3, 185-201.

Smith, E. E., Adams, N., \& Schorr, D. Fact retrieval and the paradox of interference. Cognitive Psychology, 1978, 10, 438464.

Stroop, J. R. Studies of interference in serial verbal reactions. Journal of Experimental Psychology, 1935, 18, 643-662.

Tanenhaus, M. K., Flanigan, H. P., \& Seidenbera, M. S. Orthographic and phonological activation in auditory and visual word recognition. Memory \& Cognition, 1980, 8, 513-520.

WARREN, R. E. Stimulus encoding and memory. Journal of Experimental Psychology, 1972, 94, 90-100.

Winer, B. J. Statistical principles in experimental design. New York: McGraw-Hill, 1971.

\section{NOTES}

1. We did obtain evidence for activation of body-part instruments in a previous experiment. That study also included Stroop targets that were high associates of the verb, unlike the present studies. The earlier study may indicate that body-part instruments are activated under some circumstances, or, of course, it may represent a Type I error. However, Experiments 3 and 4 indicate that body-part activation, as measured by the Stroop task, is not a general phenomenon in sentence processing.

2. Nor was there evidence for a mix of facilitatory and inhibitory processes across different trials in the in-context conditions of Experiments 1-4. It is unlikely that any such mix would have produced mean response times in context that exactly equaled those of the out-of-context conditions. Further, a mix of processes for in-context primes should have produced larger standard deviations for in-context than for out-of-context conditions. There were no noticeable differences in standard devia- 
tions for any of the comparisons of Experiments 1-4. Experiment 5 , with conscious instrument generation, did have signifi- cantly longer standard deviations for the out-of-context conditions, with longer average response times.

Appendix A

Stimuli of Experiments 1 and 2, With Completion Frequencies (F)

\begin{tabular}{|c|c|c|c|c|}
\hline \multirow[b]{2}{*}{ Sentence Prime } & \multicolumn{2}{|c|}{ Highest } & \multicolumn{2}{|c|}{ Second Highest } \\
\hline & Stroop Word & $\mathrm{F}$ & Stroop Word & $\mathbf{F}$ \\
\hline 1. He swept the floor. & broom & 100 & mop & 35 \\
\hline 2. He caught the butterfly. & net & 100 & jar & 34 \\
\hline 3. He pounded the nail. & hammer & 99 & rock & 37 \\
\hline 4. He pressed his pants. & iron & 100 & book & 17 \\
\hline 5. He wrote a letter. & pen & 100 & pencil & 84 \\
\hline 6. He located the country. & map & 98 & globe & 32 \\
\hline 7. He unlocked the door. & key & 96 & knife & 11 \\
\hline 8. He stabbed the man. & knife & 97 & icepick & 23 \\
\hline 9. He hit a homerun. & bat & 95 & stick & 37 \\
\hline 10. He drove to work. & car & 97 & bus & 30 \\
\hline 11. He tied up the hostage. & rope & 95 & cord & 16 \\
\hline 12. He dried his hands. & towel & 98 & $\mathrm{rag}$ & 23 \\
\hline 13. He stirred his coffee. & spoon & 99 & stick & 33 \\
\hline 14. He shot the robber. & gun & 88 & arrow & 11 \\
\hline 15. He pulled out the nail. & hammer & 90 & pliers & 36 \\
\hline 16. He dug a hole. & shovel & 95 & spade & 20 \\
\hline 17. He rode the wave. & surfboard & 84 & boat & 26 \\
\hline 18. He pulled the plow. & horse & 94 & tractor & 49 \\
\hline 29. He cooked dinner. & stove & 93 & fïre & 35 \\
\hline 20. He carved the wood. & knife & 92 & chisel & 30 \\
\hline 21. He called his wife. & phone & 81 & intercom & 14 \\
\hline 22. He felled the tree. & axe & 88 & saw & 48 \\
\hline 23. He watered the flowergarden. & hose & 89 & sprinkler & 45 \\
\hline 24. He cut out the article. & scissors & 95 & knife & 76 \\
\hline 25. He saw his reflection. & mirror & 92 & water & 23 \\
\hline 26. He was rushed to the hospital. & ambulance & 92 & car & 73 \\
\hline 27. He watered the lawn. & hose & 92 & sprinkler & 67 \\
\hline 28. He floated down the river. & raft & 85 & boat & 50 \\
\hline 29. He opened the wine bottle. & corkscrew & 77 & knife & 32 \\
\hline 30. He flew across the country. & plane & 81 & jet & 43 \\
\hline 31. He tightened the bolt. & wrench & 80 & pliers & 44 \\
\hline 32. He lit the cigarette. & matches & 96 & lighter & 81 \\
\hline 33. He mixed the cocktail. & glass & 85 & pitcher & 20 \\
\hline 34. He paid the bill. & check & 89 & cash & 48 \\
\hline 35. He climbed to the attic. & ladder & 94 & stairs & 46 \\
\hline 36. He shot the deer. & gun & 72 & arrow & 45 \\
\hline 37. He rode to the airport. & car & 78 & $\operatorname{taxi}$ & 28 \\
\hline 38. He held up his pants. & belt & 76 & suspender & 62 \\
\hline 39. He listened to music. & stereo & 73 & radio & 67 \\
\hline 40. He cut the grass. & mower & 62 & clippers & 25 \\
\hline 41. He drank some water. & glass & 81 & cup & 32 \\
\hline 42. He fixed his hair. & comb & 81 & brush & 73 \\
\hline 43. He tied up newspapers. & string & 74 & rope & 53 \\
\hline 44. He climbed down from the window. & ladder & 76 & rope & 58 \\
\hline 45. He blew up the ship. & bomb & 70 & dynamite & 50 \\
\hline 46. He plucked notes. & guitar & 74 & piano & 19 \\
\hline 47. He scrubbed the floor. & mop & 78 & brush & 56 \\
\hline 48. He hobbled along. & cane & 68 & crutches & 49 \\
\hline 49. He timed the race. & watch & 59 & clock & 55 \\
\hline 50. He scanned the horizon. & binoculars & 71 & telescope & 55 \\
\hline 51. He drew the picture. & pencil & 73 & pen & 40 \\
\hline 52. He moved the freight. & train & 54 & truck & 34 \\
\hline 53. He beat the man. & stick & 49 & club & 42 \\
\hline 54. He pricked his finger. & pin & 48 & needle & 43 \\
\hline 55. He wiped the counter. & sponge & 61 & rag & 54 \\
\hline 56. He lit up the room. & lights & 44 & candle & 49 \\
\hline 57. He poured the beer. & bottle & 57 & pitcher & 49 \\
\hline 58. He caught the fish. & pole & 46 & net & 39 \\
\hline 59. He illuminated the cave. & candle & 37 & flashlight & 33 \\
\hline 60. He scoured the pan. & brush & 25 & steelwool & 19 \\
\hline
\end{tabular}


Appendix B

Stimuli of Experiments 3, 4, and 5

\begin{tabular}{|c|c|c|c|}
\hline \multicolumn{2}{|c|}{ Tool Instruments } & \multicolumn{2}{|c|}{ Body-Part Instruments } \\
\hline Sentence & Test & Sentence & Test \\
\hline 1. He swept the floor. & broom & 1. He yawned after dinner. & mouth \\
\hline 2. He caught the butterfly. & net & 2. He coughed loudly. & throat \\
\hline 3. He pounded the nail. & hammer & 3. He nodded at a friend. & head \\
\hline 4. He pressed his pants. & iron & 4. He bit the apple. & teeth \\
\hline 5. He wrote a letter. & pen & 5. He typed quickly. & fingers \\
\hline 6. He located the country. & map & 6. He remembered the song. & mind \\
\hline 7. He stirred his coffee. & spoon & 7. He kicked the tire. & foot \\
\hline 8. He dried his hands. & towel & 8. He looked at the bill. & eyes \\
\hline 9. He unlocked the door. & key & 9. He kissed the child. & lips \\
\hline 10. He stabbed the man. & knife & 10. He threw the towel. & arm \\
\hline 11. He drove to work. & car & 11. He punched the bag. & fist \\
\hline 12. He dug a hole. & shovel & 12. He ran across the room. & legs \\
\hline
\end{tabular}

(Received for publication January 8, 1982;

revision accepted June 29,1982 .) 